February 2000 ・ NREL/CP-500-24791

\title{
A Conservative Control Strategy for Variable-Speed Stall-Regulated Wind Turbines
}

E. Muljadi, K. Pierce, and P. Migliore

Presented at the $19^{\text {th }}$ American Society of Mechanical Engineers (ASME) Wind Energy Symposium Reno, Nevada January 10-13, 2000
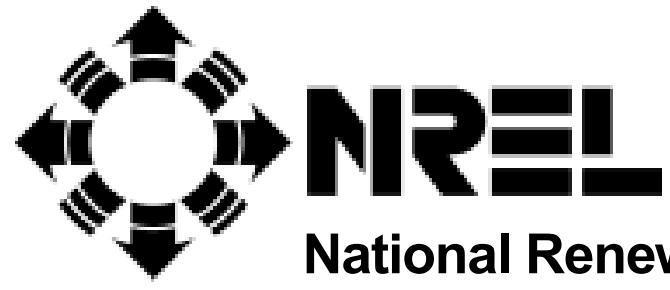

National Renewable Energy Laboratory

1617 Cole Boulevard

Golden, Colorado 80401-3393

NREL is a U.S. Department of Energy Laboratory

Operated by Midwest Research Institute $\bullet$ Battelle $\bullet$ Bechtel

Contract No. DE-AC36-99-G010337 


\section{NOTICE}

The submitted manuscript has been offered by an employee of the Midwest Research Institute (MRI), a contractor of the US Government under Contract No. DE-AC36-99G010337. Accordingly, the US Government and MRI retain a nonexclusive royalty-free license to publish or reproduce the published form of this contribution, or allow others to do so, for US Government purposes.

This report was prepared as an account of work sponsored by an agency of the United States government. Neither the United States government nor any agency thereof, nor any of their employees, makes any warranty, express or implied, or assumes any legal liability or responsibility for the accuracy, completeness, or usefulness of any information, apparatus, product, or process disclosed, or represents that its use would not infringe privately owned rights. Reference herein to any specific commercial product, process, or service by trade name, trademark, manufacturer, or otherwise does not necessarily constitute or imply its endorsement, recommendation, or favoring by the United States government or any agency thereof. The views and opinions of authors expressed herein do not necessarily state or reflect those of the United States government or any agency thereof.

Available electronically at http://www.doe.gov/bridge

Available for a processing fee to U.S. Department of Energy and its contractors, in paper, from:

U.S. Department of Energy

Office of Scientific and Technical Information

P.O. Box 62

Oak Ridge, TN 37831-0062

phone: 865.576 .8401

fax: 865.576.5728

email: reports@adonis.osti.gov

Available for sale to the public, in paper, from:

U.S. Department of Commerce

National Technical Information Service

5285 Port Royal Road

Springfield, VA 22161

phone: 800.553 .6847

fax: 703.605.6900

email: orders@ntis.fedworld.gov

online ordering: http://www.ntis.gov/ordering.htm

Printed on paper containing at least $50 \%$ wastepaper, including $20 \%$ postconsumer waste 


\title{
A CONSERVATIVE CONTROL STRATEGY FOR VARIABLE-SPEED STALL-REGULATED WIND TURBINES
}

\author{
E. Muljadi, K. Pierce, P. Migliore \\ National Renewable Energy Laboratory \\ National Wind Technology Center \\ 1617 Cole Boulevard \\ Golden, Colorado 80401, USA
}

\begin{abstract}
Simulation models of a variable-speed, fixed-pitch wind turbine were investigated ${ }^{*}$ to evaluate the feasibility of constraining rotor speed and power output without the benefit of active aerodynamic control devices. A strategy was postulated to control rotational speed by specifying the demanded generator torque. By controlling rotor speed in relation to wind speed, the aerodynamic power extracted by the blades from the wind was manipulated. Specifically, the blades were caused to stall in high winds. In low and moderate winds, the demanded generator torque and the resulting rotor speed were controlled to cause the wind turbine to operate near maximum efficiency. Using the developed models, simulations were conducted of operation in turbulent winds. Results indicated that rotor speed and power output were well regulated. Preliminary investigations of system dynamics showed that, compared to fixed-speed operation, variable-speed operation caused cyclic loading amplitude to be reduced for the turbine blades and low-speed shaft and slightly increased for the tower loads. This result suggests a favorable impact on fatigue life from implementation of the proposed control strategy.
\end{abstract}

\section{INTRODUCTION}

Wind energy conversion is the fastest growing source of new electrical generation capacity in the world, and it is expected to remain so for the next decade. In the United States, there is a growing trend for public utilities to offer renewable energy choices, or "green power" options to their customers. In Europe, the number of installed wind turbines is increasing at a dramatic pace.

Although most utility-scale wind turbines are operated at constant-speed, there is considerable interest in variable-speed turbines, as demonstrated in commercial applications by Kenetech, Enercon, Zond, and other wind turbine manufacturers. The primary advantages

\footnotetext{
* This material is declared a work of the U.S. Government and is not subject to copyright protection in the United States.
}

claimed for variable-speed turbines are increased energy capture and reduced drivetrain loads. Secondary benefits are acoustic signature and power quality. The more that is learned about variable-speed turbines, the more it becomes apparent that their behavior is significantly affected by the control strategy employed in their operation. ${ }^{1,2,3,4}$

Typically, variable-speed turbines use aerodynamic controls in combination with power electronics to regulate torque, rotor speed (rpm), and power. ${ }^{5,6}$ The aerodynamic control systems, usually variable-pitch blades or trailing-edge devices, are costly and complex and become even more so as turbines get larger. This situation provides an incentive to consider alternative control approaches. In this paper, we evaluate a variable-speed, stall-regulated strategy that eliminates the need for ancillary aerodynamic control systems. The potential benefit is a lower cost of energy resulting from lower capital cost, improved reliability, and reduced maintenance expense.

In the strategy to be investigated, the turbine is controlled to operate near maximum efficiency (energy capture) in low and moderate wind speeds. At high wind speeds, the turbine is controlled to limit its rotational speed and output power. This is accomplished by forcing the rotor into an aerodynamically stalled condition. We call this the "soft-stall" approach, because it allows the introduction of rather benign stall characteristics for purposes of controlling maximum power. Thus, in contrast to a constant-speed wind turbine, the variable-speed wind turbine has the capability of shaping the rpm-power curve. Figure 1 shows the system under consideration, with the dashed lines indicating the main control loop. The wind turbine rotor is connected to a variable-speed generator through a speed-increasing gearbox. The generator output is controlled by the power converter to follow the commanded rpm-power schedule. The generator responds to the torque command almost instantaneously. The objective of the present study is to evaluate the behavior of a variable-speed, stall- 


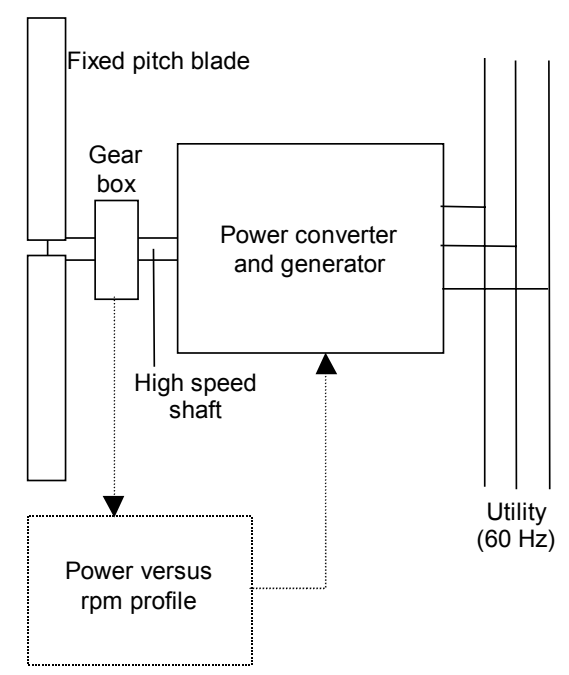

Figure 1. Physical diagram of the system.

regulated wind turbine operating in turbulent winds. This concept is explored in terms of its technical feasibility, rather than cost and reliability, which is the subject of future work.

\section{WIND TURBINE OPERATING CHARACTERISTICS}

The power $(\mathrm{P})$ converted by a wind turbine is related to the wind speed as shown in Equation 1. In the present context, the equation represents net electrical power after considering the aerodynamic efficiency of the rotor blades and the mechanical and electrical system losses. The simplest wind turbine architecture uses blades of fixed pitch operating at constant rotational speed.

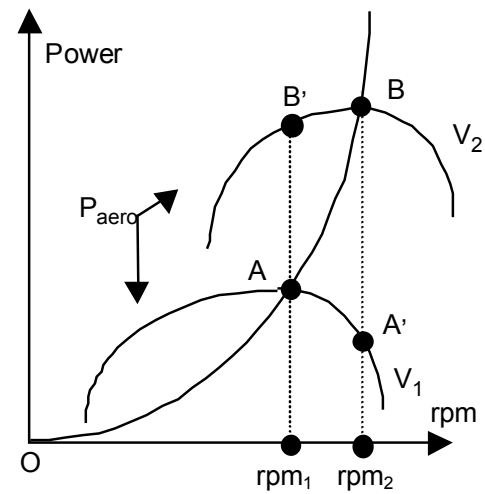

Figure 2. Power versus rpm for two different wind speeds.

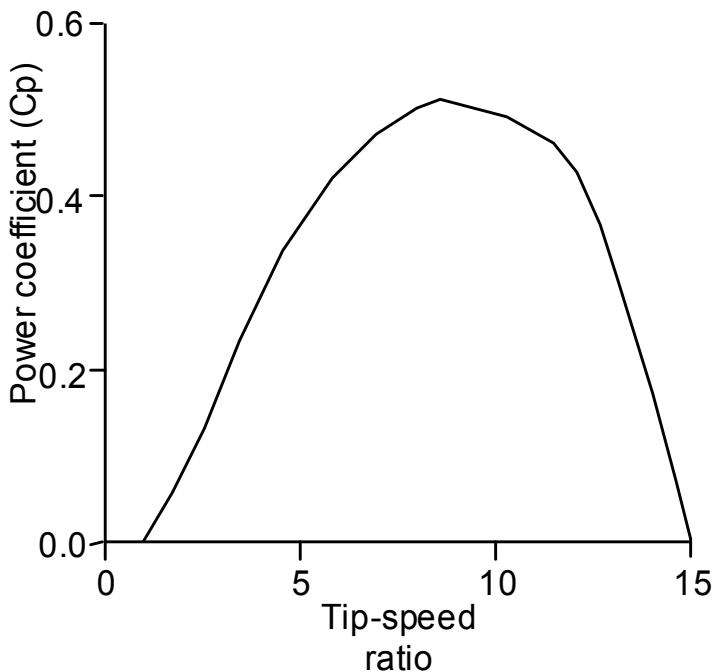

Figure 3. Power coefficient versus tip-speed ratio.

$\mathrm{P}=0.5 \rho \mathrm{AC}_{\mathrm{p}} \mathrm{V}^{3}$

where:

$\rho \quad=$ mass density of air

A $\quad=$ area swept by the rotor blades

$\mathrm{V} \quad=$ wind speed

$\mathrm{C}_{\mathrm{p}} \quad=$ nondimensional power coefficient

Figure 2 illustrates the aerodynamic power for a fixedpitch wind turbine at two different wind speeds as the $\mathrm{rpm}$ is varied. Operating at a constant rpm will maximize power only at a single wind speed. For example, if the wind turbine is operated at $\mathrm{rpm}_{1}$ and wind speed $V_{2}$ (point $B^{\prime}$ ), power conversion is not optimized. Only $\mathrm{rpm}_{1}-\mathrm{V}_{1}$ (point $\mathrm{A}$ ) is an optimum operating point for wind speed $V_{1}$. Similarly, $\mathrm{rpm}_{2}-\mathrm{V}_{1}$ (point $\mathrm{A}^{\prime}$ ) is not optimum. Only $\mathrm{rpm}_{2}-\mathrm{V}_{2}$ (point $\mathrm{B}$ ) is an optimum operating point for wind speed $\mathrm{V}_{2}$.

Figure 3 illustrates the relationship between $\mathrm{C}_{\mathrm{p}}$ and tipspeed-ratio (TSR) for a typical turbine. TSR is a nondimensional tip speed, defined as the ratio between the rectilinear speed of the blade tip and the wind speed, as shown in Equation 2.

$\mathrm{TSR}=\omega \mathrm{R} / \mathrm{V}$

For constant-speed wind turbines, an attempt is made to design the rotor blades to operate near maximum efficiency $\left(\mathrm{Cp}_{\max }\right)$ at wind speeds that occur most frequently at the design site. The rotor speed varies by only few percent (the slip) above the synchronous speed of the induction generator, but the wind speed varies 
over a wide range. Therefore, the operating point is rarely, and randomly, at the TSR for $\mathrm{Cp}_{\max }$.

For a variable-speed turbine, the objective is to continuously operate at maximum efficiency, where the resulting target power can be expressed as shown in Equation 3.

$\mathrm{P}_{\text {target }}=0.5 \rho \mathrm{AC} \mathrm{p}_{\max }\left(\mathrm{R} / \mathrm{TSR}_{\text {target }}\right)^{3} \omega^{3}$

where:

$\mathrm{R} \quad$ = radius of the rotor-blade tip

$\omega=$ rotational speed of the rotor

It is apparent from Equation 3 and Figure 3 that the power at any wind speed is maximized by operating at the tip-speed-ratio that results in the maximum power coefficient. For a variable-speed turbine, ideally, this means that as the wind speed changes, the rotor speed should be adjusted proportionally to operate continuously at the TSR for maximum $\mathrm{C}_{\mathrm{p}}$ ( $\left.\mathrm{TSR}_{\text {target }}\right)$. In the practical matter of operating a wind turbine, wind speed is not a satisfactory control parameter because of its erratic nature, time delays in its measurement, and spatial variations across the rotor. However, by simplifying Equation 3, the target power can be expressed in Equation 4 as a function of rpm; a reliable and easily measured control parameter.

$\mathrm{P}_{\text {target }}=\mathrm{K}_{1} \omega^{3}=\mathrm{K}_{2}(\mathrm{rpm})^{3}$

In variable-speed operation, the inertia of the wind turbine rotor affects the turbine's dynamic behavior. The rotor inertia is very large compared to the inertia of the gearbox, generator, and other rotating components. Rotor inertia is analogous to an inductor in an electrical circuit. It helps smooth, but not eliminate, rpm variations by storing energy during acceleration and restoring energy during deceleration. A simple illustration is provided in Figure 4, where it is assumed that the wind turbine is operating at a constant $C \mathrm{p}_{\max }$. In Figure 4:

- $\mathrm{P}_{\text {wind }}$ is the maximum power that can be extracted from the wind.

- $\mathrm{P}_{\text {captured }}$ is the mechanical power that is actually captured in the turbine rotor.

- $P_{\text {electric }}$ is the mechanical power converted to electric power by the generator.

When the captured power $\left(\mathrm{P}_{\text {captured }}\right)$ is higher than the generator power $\left(\mathrm{P}_{\text {electric }}\right)$, the rotor accelerates and its kinetic energy increases. Of course, the converse is also true. The rate of change in kinetic energy is equal to the difference between the captured power and the
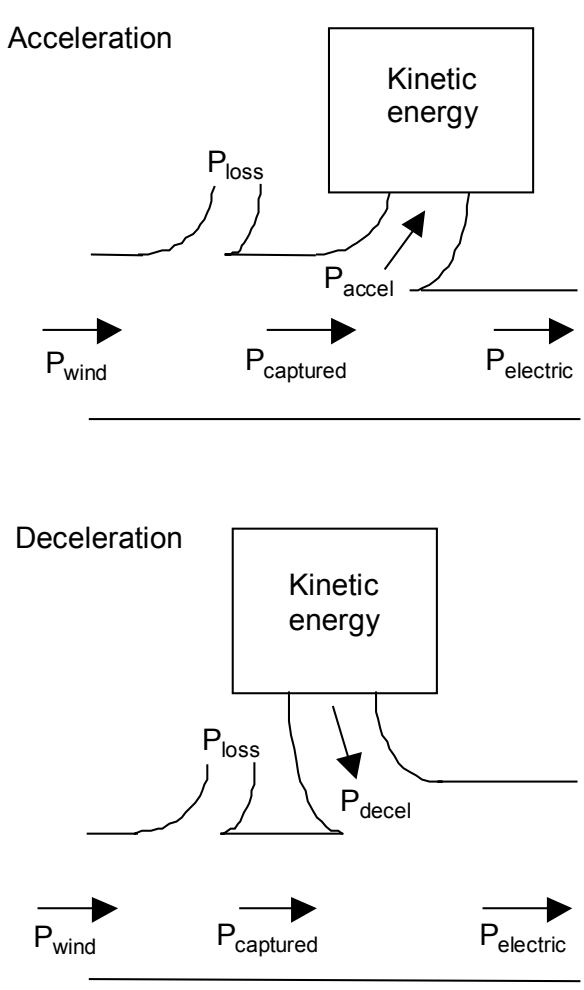

Figure 4. Kinetic energy in the turbine at constant
Cp during acceleration and deceleration.

generator power. This difference, labeled $\mathrm{P}_{\text {accel }}$ or $\mathrm{P}_{\text {decel }}$ in Figure 4, accelerates or decelerates the rotor and drives operation toward the TSR for $\mathrm{Cp}_{\max }$. Delays in the change of rotor speed due to the inertia of the rotor prevent continuous operation at $\mathrm{Cp}_{\max }$ in varying winds. However, operation will be closer to optimum than for constant-speed operation.

Operation of the wind turbine along its Cp-TSR curve governs the power captured from the wind. Figure 5 illustrates the power flow at both maximum $\mathrm{Cp}$ and Stalled $\mathrm{Cp}$. At maximum $\mathrm{Cp}$, aerodynamic efficiency is at its maximum and the power captured from the wind is at its optimum. In a stalled condition, the power captured from the wind is not at its optimum. The difference between the maximum power that could be captured and the power that is actually captured is called $\mathrm{P}_{\text {loss. }}$. The wind turbine can be forced to operate in a stalled condition if the generator is loaded higher than it would be at the $\mathrm{Cp}_{\max }$ operating point. The wind turbine will then operate at a lower TSR and Cp. This approach is suitable for wind turbines that do not have aerodynamic control devices (and the ability to spill power by aerodynamic means), and it is the basis of the control strategy evaluated in the present study. 


\section{Maximum $\mathrm{Cp}$}

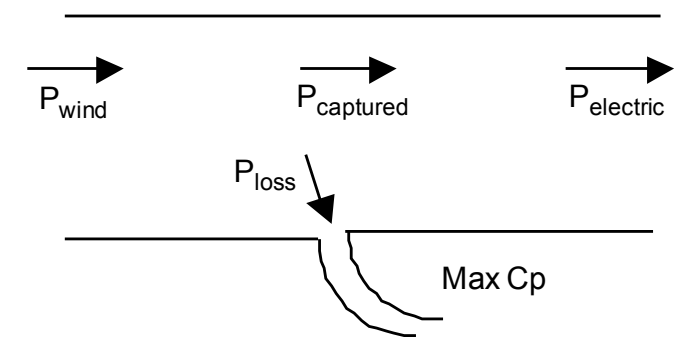

Stall $\mathrm{Cp}$

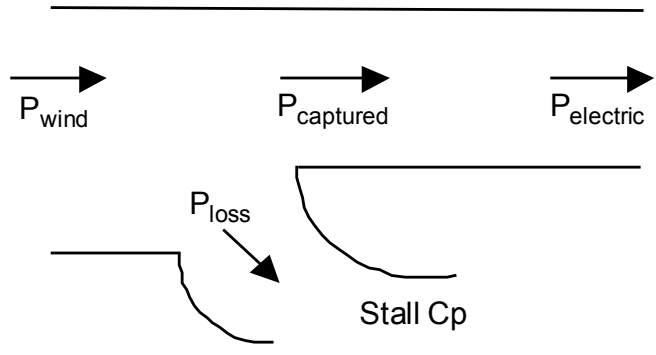

Figure 5. Power flow at different power coefficients at constant-speed.

\section{CONTROL STRATEGY}

Most turbines are designed for a maximum rated power. The power available from the wind is proportional to the cube of the wind speed. Therefore, to regulate power as the wind speed increases, there must be a mechanism to reduce the efficiency of the rotor blades. Constant-speed, fixed-pitch wind turbines accomplish this automatically; at high wind speeds their blades stall. The resulting reduction in lift and increase in drag dramatically reduces the ability of the blades to extract power from the wind. It is important to note that this will be the case only if the generator (and power converter, in our case) can limit the rotor rpm, thereby forcing the blades to stall. And the blades should stall gently, so that mechanical loading on the wind turbine components is not significantly increased.

Figure 6 illustrates the relationship between power, wind speed, and rpm for a typical wind turbine at two constant rotor speeds. The lower the operating rpm of the rotor, the lower the maximum power that can be generated. Thus, the turbine operated at rotor speed $\mathrm{rpm}_{\mathrm{D}}$ will have a maximum power of $\mathrm{P}_{\mathrm{D}}$, and the turbine operated at rotor speed $\operatorname{rpm}_{\mathrm{C}}$ will have a maximum power of $\mathrm{P}_{\mathrm{C}}$. This concept is the basis of the power profile for variable-speed operation, as shown in Figure 7.

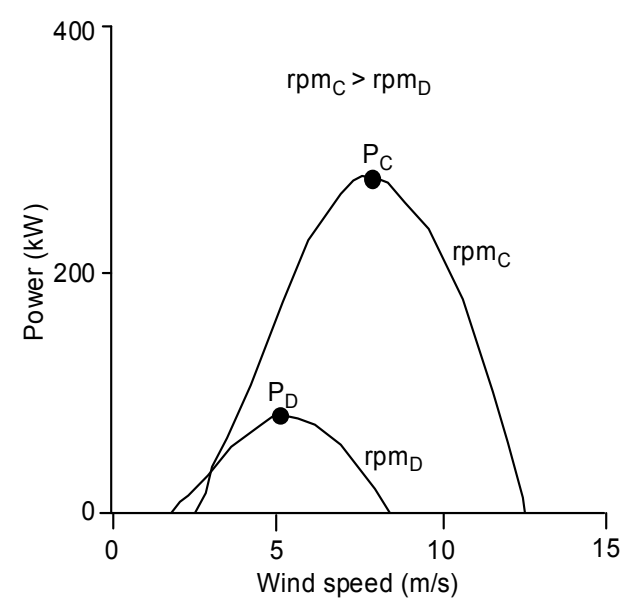

Figure 6. Power versus wind speed at two different rotor speeds.

As noted above, rotor acceleration can be made zero as long as the power extracted from the wind, less drivetrain losses, is equal to the electric power output of the generator. This relationship is described by Equation 5 in terms of torque. The rotor acceleration $(\mathrm{d} \omega / \mathrm{dt})$ is inversely proportional to the inertia of the rotating system, essentially the rotor inertia (J), and directly proportional to the difference between the torque applied by the wind $\left(\mathrm{T}_{\text {captured }}\right)$ and the electric torque of the generator ( $\left.\mathrm{T}_{\text {electric }}\right)$. The aerodynamic torque is affected by the operating $\mathrm{Cp}$.

$\mathrm{d} \omega / \mathrm{dt}=\left[\mathrm{T}_{\text {captured }}-\mathrm{T}_{\text {electric }}\right] / \mathrm{J}$

Figure 7 illustrates the control strategy. At low and moderate wind speeds (OA), generator $\mathrm{rpm}$ is

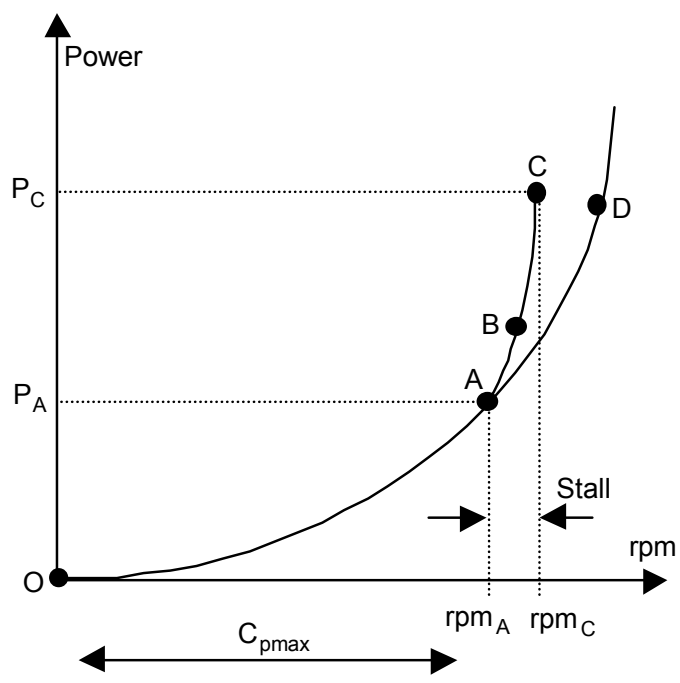

Figure 7. Power target versus rpm. 
controlled so that maximum power is produced by operating near $\mathrm{Cp}_{\max }$. In high winds, the turbine is prevented from following the $\mathrm{Cp}_{\max }$ trajectory (OD) and is forced to operate at a lower TSR and Cp. At $\mathrm{rpm}_{\mathrm{A}}$, the applied generator torque causes the turbine to deviate from $\mathrm{Cp}_{\max }$ operation. Because the difference between $\mathrm{P}_{\text {captured }}$ and $\mathrm{P}_{\text {electric }}$ is positive, the rotor speed continues to increase, but the turbine blades begin to operate in a partially stalled mode. It is expected that the rotor speed will be controllable and constrained to an upper limit of $\mathrm{rpm}_{\mathrm{C}}$. The rpm range between $\mathrm{rpm}_{\mathrm{A}}$ and $\mathrm{rpm}_{\mathrm{c}}$ is the "soft stall" region. To successfully implement this strategy, the power converter and generator must be sized, with appropriate safety margins, to process power $\mathrm{P}_{\mathrm{C}}$ to limit the rotor speed to $\operatorname{rpm}_{C}$. Thus, when the rotor speed reaches $\operatorname{rpm}_{C}$, the aerodynamic power and the electric power are balanced, and the rotor acceleration is zero.

\section{ANALYSIS AND RESULTS}

We developed a simulation model of a two-blade, downwind, variable-speed, fixed-pitch wind turbine with a nominal rated power of $275 \mathrm{~kW}$. Its wound-rotor induction generator is controlled by a series-resonant power converter using the flux orientation method, which permits torque control at any rpm. The output of the generator stator is fed directly to the utility at $60 \mathrm{~Hz}$ and unity power factor. The output of the generator rotor is processed through the power converter before it is returned to the utility at $60 \mathrm{~Hz}$ and unity power factor. Using a wound-rotor (doubly-fed) generator allows the power converter to be much smaller than would be required in a similar system using a conventional squirrel-cage induction generator.

The generator, controlled to provide the desired torquespeed relationship, was modeled as a wound-rotor induction generator with its stator connected to the utility and its rotor-winding connected to the power converter. The torque-speed relationship allowed the wind turbine to operate at its optimum power coefficient in low and moderate wind speeds, which account for most of the energy capture at typical wind sites. In high winds, the torque was controlled to limit rotor speed, which stalls the blades and constrains power. The transition from medium to high wind speeds must be done smoothly, and requires a trade-off between energy capture and load reduction that was not part of the present study.

Two simulation methods were used to evaluate the proposed control strategy: Advanced Continuous Simulation Language (ACSL) and Automatic Dynamic
Analysis of Mechanical Systems (ADAMS). ACSL is oriented towards electrical power considerations. ADAMS is oriented towards aerodynamics and structural dynamics. In both approaches, it was necessary to select practical limits for the simulated wind turbine. The maximum rotor speed (point $\mathrm{C}$ in Figure 7) chosen was $62 \mathrm{rpm}$ and the point at which stall is induced (point A in Figure 7) was $57 \mathrm{rpm}$, which corresponds to the speed at which a comparable constant-speed turbine would operate. The maximum capacity of the drivetrain and electrical system chosen was $400 \mathrm{~kW}$. The target TSR was 8.5 and the corresponding $\mathrm{Cp}$ was 0.46 .

\section{ACSL Simulations}

A computer model of the system was developed to predict aerodynamic power as a function of wind speed and rotor rpm. Required inputs include blade geometry, rotor inertia, drivetrain inertia, and stiffness and damping of the rotating shafts. The aerodynamic characteristics of the wind turbine are defined by the relationship between its nondimensional power output and tip speed. The wind speed input used to drive the model is stored in a data file. Although any temporal distribution (and turbulence level) can be chosen, we used a 10-minute time series to reduce computational time. Output is in the form of high- and low-speed shaft torques as a function of time.

A segment of the assumed wind speed distribution, which ranges from $10 \mathrm{~m} / \mathrm{s}$ to $35 \mathrm{~m} / \mathrm{s}$ and has a mean value of $18 \mathrm{~m} / \mathrm{s}$, is shown in the upper part of Figure 8 , which depicts results of the ACSL simulations. The calculated power coefficient, shown in the lower part of Figure 8 , follows the control strategy as evidenced by the dramatic reduction in $\mathrm{Cp}$ (blades stalled) at high

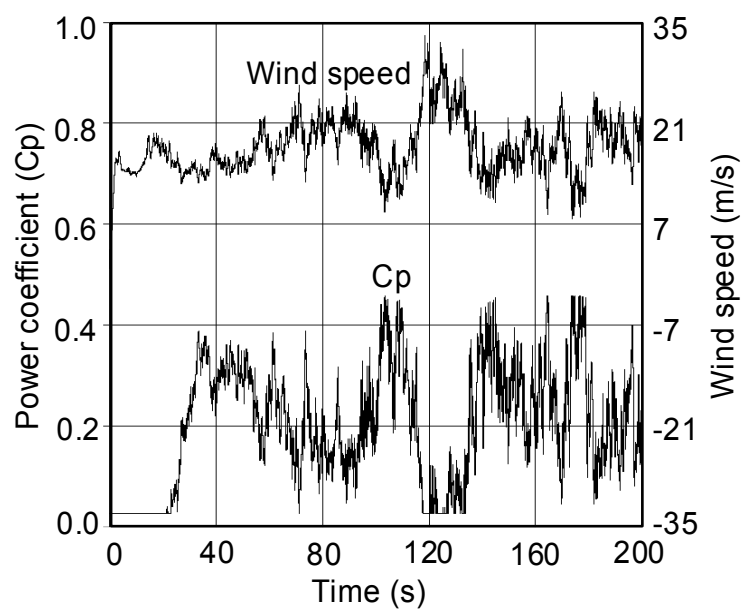

Figure 8. Wind speed $(\mathrm{m} / \mathrm{s})$ and power coefficient $\mathrm{Cp}$ 


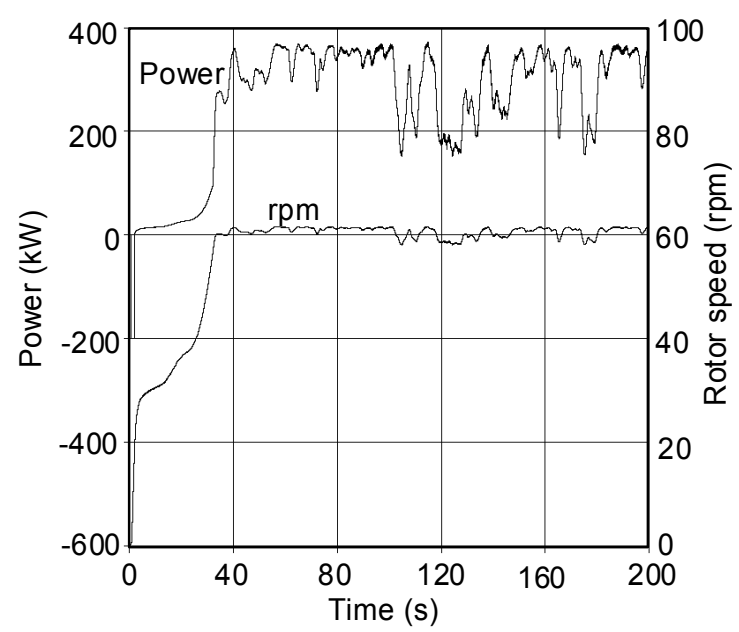

Figure 9. Power (kW) and rotor speed (rpm)

wind speeds, around $t=120$. At the low wind speeds, around $\mathrm{t}=110,140$, and 175 , the control strategy succeeds in maintaining $\mathrm{Cp}$ near its maximum possible value.

The calculated power and rpm are shown in Figure 9. The system is started with the generator operating as a motor at a constant power of 200 kilowatts. As the rpm increases, the start-up procedure is discontinued and the normal operating mode is simulated. At high wind speeds, the rotor speed and power are successfully limited to approximately $61 \mathrm{rpm}$ and $385 \mathrm{~kW}$, respectively. Because the rotor rpm dictates the power output of the generator, the power variation follows the $\mathrm{rpm}$ variation. Note that as the wind speed fluctuates at its higher values, the rotor blades operate in a stalled condition. This is evidenced by the reduction in rpm and power at high wind speeds around $t=120$. The rotor slows as it stalls. As hypothesized, the rotor speed never exceeds $62 \mathrm{rpm}$ and the power never exceeds 400 $\mathrm{kW}$. In fact, it appears that the assumed capacity of the power converter and generator may be somewhat conservative.

Although it is difficult to ascertain in Figure 9, the following observations can be made. As the wind speed increases, at around $t=110$, the captured power also increases. Because the captured power is higher than the electrical power, the rotor accelerates. When the rpm reaches the stalling range, the demanded generator torque is raised to follow a stalling torque profile. At rotor speeds less than $57 \mathrm{rpm}$, the controller follows the $\mathrm{Cp}_{\max }$ operating mode described by Equation 4. That is, the electric power is controlled to be a cubic function of rpm. From $57 \mathrm{rpm}$ to $62 \mathrm{rpm}$, the turbine operates in the stalling mode.

\section{ADAMS Simulations}

Simulations were also performed with an ADAMS model $^{5}$ using specialized aerodynamic ${ }^{6}$ and wind-inflow turbulence subroutines. ${ }^{7}$ The model, originally developed to represent a constant-speed wind turbine operating at $57 \mathrm{rpm}$, was modified to operate using the described variable-speed control strategy with a rotorspeed range of 30 to $62 \mathrm{rpm}$. The simulations were performed using 10-minute time series of Kaimal turbulence at mean wind speeds of $7 \mathrm{~m} / \mathrm{s}$ and $21 \mathrm{~m} / \mathrm{s}$ to study the impact of high turbulence on the two different operating methods (constant speed and variable speed).

For variable-speed operation in high winds, the cyclic loading on most components was very similar to that for constant-speed operation. A notable exception is the drivetrain, in which the variable-speed generator mimics a high-slip induction generator. A consequent softening of the drivetrain reduces the twice-per-revolution power oscillations typically seen for a constant-speed teetering rotor. Thus, for variable-speed operation, most of the rotor-torque oscillations are absorbed by small variations in rotor speed, resulting in reduced power oscillations and drivetrain torque inputs. This important effect (noted at all wind speeds) is illustrated in Figure 10 , which compares time-series simulations of power output for constant-speed and variable-speed operation at a mean wind speed of $21 \mathrm{~m} / \mathrm{s}$. The power levels are different, because, at this wind speed, the variablespeed control algorithm calls for operation at a higher rpm (higher power) than the constant-speed turbine. For the same reason, the torque histogram in Figure 11 shows that the mean value of torque is elevated for the variable-speed case. But the distribution is narrower, indicating that for equivalent power output and rotor

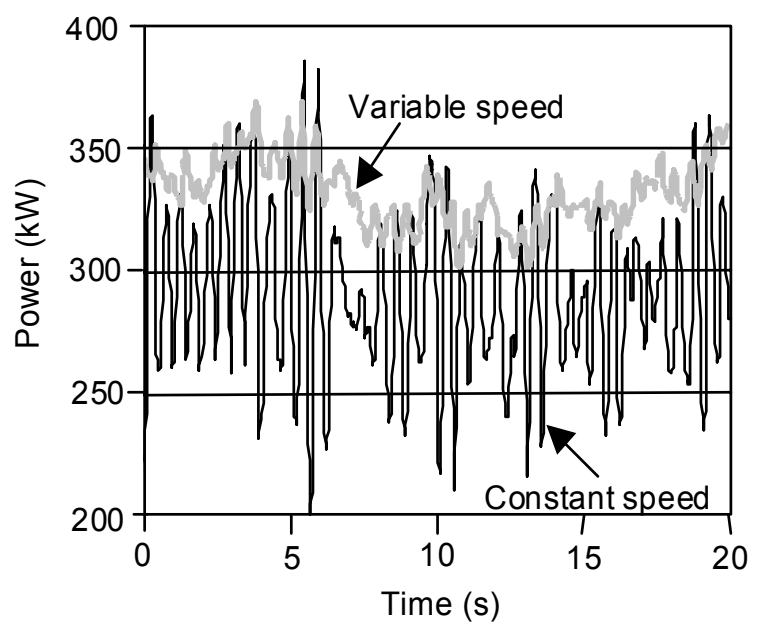

Figure 10. Time series of power output for both constant-speed and variable-speed operation at $21 \mathrm{~m} / \mathrm{s}$ average wind speed 


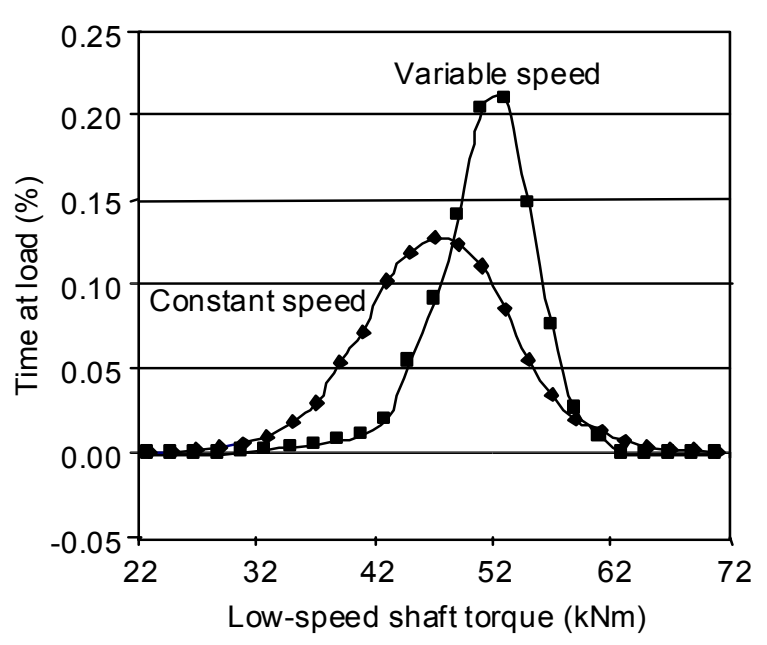

Figure 11. Histogram of low-speed-shaft torque

speed, high-torque inputs to the gearbox would be reduced.

For variable-speed operation in low winds, cyclic rootflap blade loading is decreased while tower loading is somewhat increased. The decreased blade loading results from an improved balance of aerodynamic and centrifugal forces on the blades. The increased tower loading results from occasional operation at or near a tower natural frequency. Rainflow cycle counts of rootflap moment and tower-top displacements are shown in Figures 12 and 13 for a mean wind speed of $7 \mathrm{~m} / \mathrm{s}$.

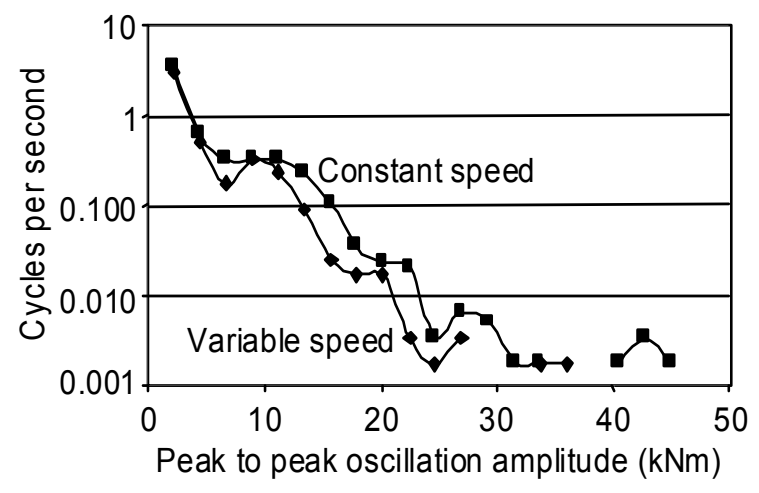

Figure 12. Rainflow cycle counts of root flap moment for a mean wind speed of $7 \mathrm{~m} / \mathrm{s}$.

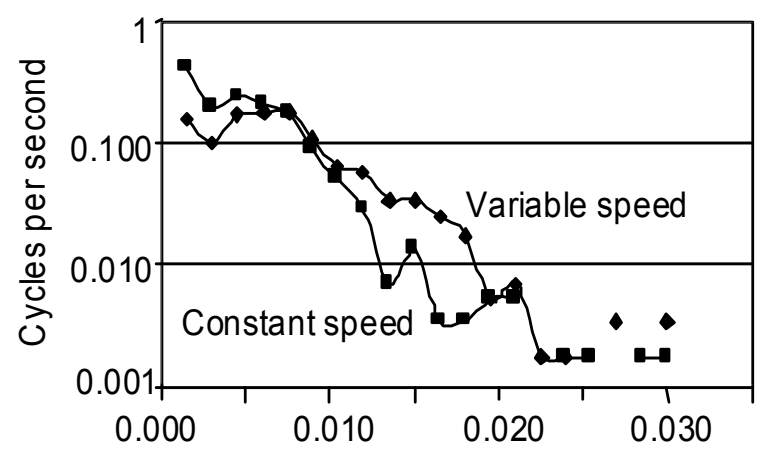

Peak to peak oscillation amplitude $(\mathrm{m})$

Figure 13. Rainflow cycle counts of tower top displacement for a mean wind speed of $7 \mathrm{~m} / \mathrm{s}$.

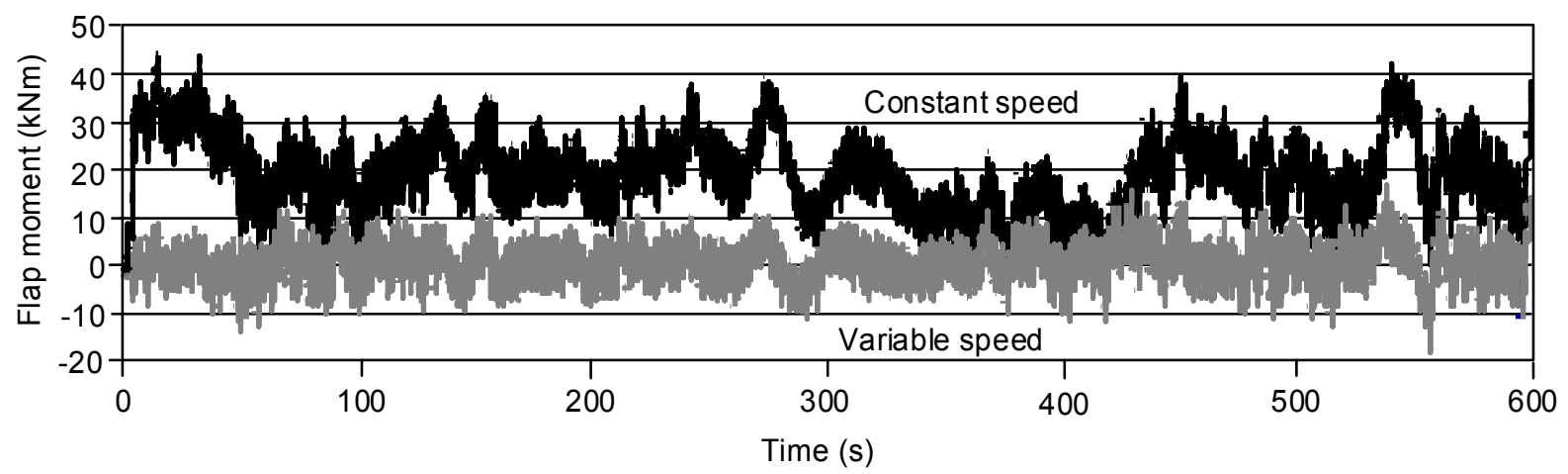

Figure 14. The time trace of flap moment for constant-speed and variable-speed operation.

Further insight into the reduction of flap cyclic loads is gained from the time-series simulation shown in Figure 14. The time trace of flap moment is smoother for variable-speed operation, because of the improved balance of aerodynamic and inertial loading, with a peak-to-peak variation about the mean of approximately $10 \mathrm{kNm}$. The mean is also reduced because of the improved balance of loads. For constant-speed operation, the variation and mean are greater.

\section{CONCLUSIONS}

A control strategy was postulated for variable-speed, stall-regulated wind turbines. Computational models were developed and simulations were conducted of operation in turbulent winds. The following conclusions may be drawn from the simulation results.

Controlling the rotor rpm, and hence the tip-speed ratio, by controlling the generator torque promotes adherence 
to a desired power coefficient profile. At low and moderate wind speeds, operation at or near $\mathrm{Cp}_{\max }$ may be achievable. At high wind speeds, by forcing the rotor blades to stall, rpm and power can be constrained to the desired limits.

A preliminary investigation of dynamic loads indicated that drivetrain fatigue loads in all wind speeds are reduced for variable-speed operation. In low winds, blade flap-loads are somewhat reduced for variablespeed operation, although tower loads are slightly increased. In high winds, blade flap-loads and tower loads are approximately the same for variable-speed and constant-speed operation. In addition, the twice-perrevolution power fluctuations typical of teetered rotors were substantially reduced by variable-speed operation.

These simulations were performed without regard to issues of wind-turbine cost or reliability. These matters, as well as those related to changes in atmospheric density, blade soiling, and site-specific conditions, will be the subject of future studies.

\section{ACKNOWLEDGMENTS}

Neil Kelley and Marshall Buhl Jr. of NREL provided the wind data used in the ACSL simulations. The U.S. Department of Energy supported the project under contract number DE-AC36-98GO10337.

\section{REFERENCES}

1 Muljadi, E.; Butterfield C.P.; Migliore, P. "Variable-speed Operation of Generators with RotorSpeed Feedback in Wind Power Applications." Presented at the ASME Wind Energy Symposium 1996, Houston, Texas, January 28-February 2, 1996.

2 Muljadi, E.; Pierce, K; Migliore, P. "Control Strategy for Variable-Speed, Stall-Regulated Wind Turbines." Presented at the American Control Conference 1998, Philadelphia, Pennsylvania, June 2830, 1998.

3 Fardoun, A.A.; Fuchs, E.F.; Carlin, P.W. "A Variable-speed, Direct Drive Transmission Wind Power Plant." Proceedings of Windpower '93, San Francisco, CA, July 12-16, 1993. Washington, D.C.: American Wind Energy Association; pp. 134-141.

4 Connor B.; Leithead, W.E. "Relationship of the Controllability of Power/Torque Fluctuations in the Drive-Train to the Wind Turbine Configuration." 1993 Wind Energy Conversion 1993, Fifteenth BWEA Wind
Energy Association Conference, York, October 6-8, 199. London, United Kingdom, Mechanical Engineering Limited.

5 Wright, A., Osgood, R.O., Malcolm, D.J. "Analysis of a Two-Bladed, Teetering-Hub Turbine Using the ADAMS $®$ Software." Presented at Windpower '94, Minneapolis, Minnesota, May 9-13, 1994.

6 Hansen, A.C., Users Guide to the Wind Turbine Dynamics Computer Programs YawDyn and AeroDyn for ADAMS. Mechanical Engineering Department, University of Utah, Salt Lake City, Utah, 1996.

7 Kelley, N.D. "Full-Vector (3-D) Inflow Simulations in Natural and Wind Farm Environments Using an Expanded Version of the SNLWind (Veers) Turbulence Code." Presented at the Twelfth ASME Wind Energy Symposium, Houston, Texas, 1993. 